\title{
Competing transfer pathways in direct and indirect dynamic nuclear polarization magic anglespinning nuclear magnetic resonance experiments on HIV-1 capsid assemblies: implications for sensitivity and resolution
}

\author{
Ivan V. Sergeyev ${ }^{1}$, Caitlin M. Quinn ${ }^{2}$, Jochem Struppe ${ }^{1}$, Angela M. Gronenborn ${ }^{3,4}$, and \\ Tatyana Polenova ${ }^{2,3}$ \\ ${ }^{1}$ Bruker Biospin Corporation, 15 Fortune Drive, Billerica, MA 01821, United States \\ ${ }^{2}$ Department of Chemistry and Biochemistry, University of Delaware, Newark, DE 19716, United States \\ ${ }^{3}$ Pittsburgh Center for HIV Protein Interactions, University of Pittsburgh School of Medicine, 1051 Biomedical \\ Science Tower 3, 3501 Fifth Avenue, Pittsburgh, PA 15261, United States \\ ${ }^{4}$ Department of Structural Biology, University of Pittsburgh School of Medicine, 3501 Fifth Ave., \\ Pittsburgh, PA 15261, United States
}

Correspondence: Tatyana Polenova (tpolenov@udel.edu) and Angela M. Gronenborn (amg100@ pitt.edu)

Received: 30 January 2021 - Discussion started: 4 February 2021

Revised: 23 March 2021 - Accepted: 23 March 2021 - Published: 27 April 2021

\begin{abstract}
Dynamic nuclear polarization (DNP)-enhanced magic angle spinning (MAS) nuclear magnetic resonance (NMR) of biological systems is a rapidly growing field. Large signal enhancements make the technique particularly attractive for signal-limited cases, such as studies of complex biological assemblies or at natural isotopic abundance. However, spectral resolution is considerably reduced compared to ambient-temperature non-DNP spectra. Herein, we report a systematic investigation into sensitivity and resolution of $1 \mathrm{D}$ and 2D ${ }^{13}$ C-detected DNP MAS NMR experiments on HIV-1 CA capsid protein tubular assemblies. We show that the magnitude and sign of signal enhancement as well as the homogeneous line width are strongly dependent on the biradical concentration, the dominant polarization transfer pathway, and the enhancement buildup time. Our findings provide guidance for optimal choice of sample preparation and experimental conditions in DNP experiments.
\end{abstract}

1

Introduction

Since the seminal reports of dynamic nuclear polarization (DNP)-enhanced magic angle spinning (MAS) nuclear magnetic resonance (NMR) experiments in biological systems by Griffin and coworkers in the early 2000s (Bajaj et al., 2003; Rosay et al., 2003, 2001), the field has evolved rapidly. Commercial instrumentation operating at magnetic fields from 9.4 to 21.1 T has enabled the use of DNP technology by multiple NMR groups across the globe. Today, DNP MAS NMR is used in structural studies of a broad range of biological sys- tems, including soluble proteins (Jeon et al., 2019), amyloid fibrils and nanocrystals (Bayro et al., 2011; Debelouchina et al., 2013; Frederick et al., 2017; van der Wel et al., 2006; Debelouchina et al., 2010), membrane proteins (Rosay et al., 2003; Cheng and Han, 2013; Tran et al., 2020; Salnikov et al., 2017; Smith et al., 2015; Wylie et al., 2015), nucleic acids (Wenk et al., 2015), viruses and viral protein assemblies (Gupta et al., 2016; Jaudzems et al., 2018; Gupta et al., 2019; Lu et al., 2019; Rosay et al., 2001; Sergeyev et al., 2011), biomaterials (Koers et al., 2013; Ravera et al., 2015; VigerGravel et al., 2018), unfolded and misfolded proteins (König 
et al., 2019), and intact cells (Viennet et al., 2016; Albert et al., 2018; Judge et al., 2020; Yamamoto et al., 2015), including at natural isotopic abundance (Viger-Gravel et al., 2018; Takahashi et al., 2012). The key advantage of DNP-enhanced MAS NMR is the tremendous sensitivity enhancements afforded by the transfer of polarization from electron spins to nuclear spins. Sources of electron spins are either endogenous paramagnetic groups in the molecule (Maly et al., 2012) or externally added paramagnetic species (Hu et al., 2004). Theoretical maximum DNP enhancement factors, $\varepsilon$, are $\sim 660\left({ }^{1} \mathrm{H}\right), 2624\left({ }^{13} \mathrm{C}\right)$, and $6511\left({ }^{15} \mathrm{~N}\right)$. In practice, observed DNP enhancement factors depend on a number of factors but primarily the class of molecule being investigated, the paramagnetic species used, and the magnetic field. For instance, record DNP signal enhancements of $\varepsilon=35-41$ have been reported on a histidine impregnated with the biradical HyTEK2 in 1,1,2,2-tetrachloroethane at a magnetic field of $21.15 \mathrm{~T} / 900 \mathrm{MHz}$ (Berruyer et al., 2020). To date, no soluble DNP polarization agents suitable for experiments in biological systems at such high fields have been reported. Not unexpectedly, experimental DNP enhancements in biological systems vary widely, depending on the magnetic field strength, the type and concentration of radical/biradical, the temperature, the MAS frequency, and the nature of the sample. The highest reported ${ }^{1} \mathrm{H}$ enhancement for a biological molecule is $\varepsilon=250$ (Wenk et al., 2015); the largest gains have been observed at moderate magnetic fields (9.4-14.1 T), such as $\varepsilon=148$ for direct ${ }^{13} \mathrm{C}$ excitation in perdeuterated microcrystalline SH3 (Akbey et al., 2010) and $\varepsilon=64-100$ for CPbased ${ }^{13} \mathrm{C}$ and direct ${ }^{19} \mathrm{~F}$ excitation in fully protonated HIV-1 capsid tubes (Gupta et al., 2016, 2019; Lu et al., 2019). For membrane proteins, sensitivity gains in the range $\varepsilon=20$ 100 are generally accessible (Liao et al., 2016; Yamamoto et al., 2015; Tran et al., 2020) at lower magnetic fields, depending on sample preparation, and reduce to $\varepsilon=4-10$ for protein-tagged radicals (Wylie et al., 2015) and at higher magnetic fields of $18.8 \mathrm{~T}$ (Gupta et al., 2016).

The sensitivity gains offered by DNP open new avenues for characterization of biological systems intractable by conventional MAS NMR techniques. Unfortunately, these gains are often accompanied by a loss of resolution (Can et al., 2015; Geiger et al., 2016). At cryogenic temperatures of $120 \mathrm{~K}$ and lower, where signal enhancements are the highest, severe broadening of spectral lines is common, limiting widespread applications to biological systems. Sources for reduced resolution are varied, caused by either freezing-out of different conformational substates (Linden et al., 2011), paramagnetic broadening (Rogawski et al., 2017; Gupta et al., 2016), or both. Interestingly, some systems, such as HIV1 capsid assemblies (Gupta et al., 2016, 2019), bacterial T3SS needles formed by MxiH protein (Fricke et al., 2016), Pf1 phage (Sergeyev et al., 2017), and Acinetobacter phage 205 capsid (Jaudzems et al., 2018), yield well-resolved DNP MAS NMR spectra; for others, such as disordered systems, the resolution is very poor (reviewed in König et al., 2019).
While it appears that large signal enhancements and high spectral resolution can be observed in DNP experiments of ordered rigid systems, a systematic understanding of sample and experimental conditions required to attain maximum sensitivity and resolution is lacking. One important consideration in the sample preparation relates to the concentration of the paramagnetic polarization agent, most commonly a biradical such as TOTAPOL (Song et al., 2006) or AMUPol (Sauvée et al., 2013). For most biological studies to date, biradical concentrations range from 8 to $28 \mathrm{mM}$ (reviewed in Jaudzems et al., 2019). Also of critical importance is the DNP polarization transfer pathway (Thankamony et al., 2017; Aladin and Corzilius, 2019, 2020). Although distinct polarization transfer pathways have been discussed to underlie the different DNP mechanisms, we will restrict discussion here to only the three-spin-flip mechanism known as the cross-effect (CE) (Hu et al., 2004) due to its unique position in the DNP field profile. Notably, even CE DNP encompasses several possible transfer pathways, each with a unique signature. In the indirect pathway, the electron polarization is first transferred from the radicals' electrons to the surrounding protons, followed by spin diffusion throughout the proton spin network and subsequent transfer of the proton polarization to the nucleus of interest by cross-polarization (CP). This pathway is exploited in most of the DNP experiments to date and yields high signal enhancements with short buildup times and relatively narrow lines, unaffected by paramagnetic broadening (Aladin and Corzilius, 2020). The direct DNP process entails coherent transfer of electron polarization to the nucleus of interest without any involvement of the proton spin network. Its drawbacks are significant paramagnetic broadening and low efficiency due to its slow spread (Aladin and Corzilius, 2020). However, as an advantage, direct DNP experiments permit the detection of sites close to the paramagnetic centers. Simultaneously with the direct DNP effect, an indirect, incoherent DNP transfer, dubbed SCREAM-DNP, may occur, driven by molecular motion-associated heteronuclear cross-relaxation (Aladin and Corzilius, 2019). This pathway results in small negative signal enhancements, typically on or around mobile groups such as methyls.

Herein, we report on a systematic study of ${ }^{13} \mathrm{C}$ DNP signal enhancements and spectral resolution for tubular assemblies of HIV-1 CA capsid protein. These CA capsid assemblies have been extensively characterized in our laboratory, including by ${ }^{13} \mathrm{C}$ and ${ }^{19} \mathrm{~F}$ DNP-enhanced MAS NMR (Lu et al., 2019; Gupta et al., 2019, 2016). For the experiments described here, the samples were prepared with 4.3, 22.8, and $28.2 \mathrm{mM}$ AMUPol. All three polarization transfer pathways were detected: indirect, direct, and SCREAM-DNP. Overall, the dominant pathway is determined by the biradical concentration in the sample and the recycle delay or the time allotted for DNP signal buildup. The magnitude and sign of the signal enhancements as well as line widths are strongly dependent on the biradical concentration and the polarization transfer 
pathway; 89- and 6.4-fold ${ }^{13} \mathrm{C}$ signal enhancements were detected in CP and direct-polarization (DP) experiments. Our findings also reconcile the large variations in signal enhancements and resolution reported by different research groups.

Taken together, the results presented and discussed here are exciting and indicate that it is possible to select a desired DNP transfer pathway, and hence the information content of the spectra, by judicious choice of sample preparation and experimental conditions, thus further highlighting the unique capabilities of DNP-enhanced MAS NMR applications for structural biology.

\section{Materials and methods}

\subsection{Samples}

5F-Trp, U- ${ }^{13} \mathrm{C},{ }^{15} \mathrm{~N}$-labeled CA (NL4-3 strain) was expressed and purified as described in our previous report ( $\mathrm{Lu}$ et al., 2019). Tubular assemblies of CA were prepared from $30 \mathrm{mg} \mathrm{mL}^{-1}$ protein solutions in $25 \mathrm{mM}$ phosphate buffer ( $\mathrm{pH}$ 6.5) containing $2.4 \mathrm{M} \mathrm{NaCl}$, by incubation at $37^{\circ} \mathrm{C}$ overnight. The DNP samples were prepared following our previously established protocols (Gupta et al., 2016). In brief, the biradical, AMUPol (15-\{[(7-oxyl-3,11-dioxa-7-azadispiro[5.1.5.3]hexadec-15yl)carbamoyl][2-(2,5,8,11-tetraoxatridecan-13-ylamino) \}[3,11-dioxa-7-azadispiro[5.1.5.3]hexadec-7-yl])oxidanyl)

(Sauvée et al., 2013) was added to $11.0,11.7$, and $11.6 \mathrm{mg}$ of pelleted tubes. To dissolve the AMUPol, the pellets were gently stirred; $20 \%(v / v)$ glycerol-d $\mathrm{d}_{8}$ buffer containing $1 \mathrm{M}$ $\mathrm{NaCl}$ was added on top, without disturbing the pellet. The sample was incubated overnight at $4{ }^{\circ} \mathrm{C}$. Excess glycerol solution was removed, and the samples were transferred to $1.9 \mathrm{~mm}$ rotors for subsequent DNP experiments. Final concentrations of $4.3,22.8$, and $28.2 \mathrm{mM}$ were measured using a Bruker EMXnano benchtop EPR spectrometer directly on the packed DNP-NMR rotors prior to DNP experiments.

\subsection{MAS NMR spectroscopy}

DNP-enhanced MAS NMR spectra of CA tubular assemblies were acquired in the Bruker Billerica laboratories on an Avance III-HD SSNMR spectrometer equipped with a $1.9 \mathrm{~mm}$ triple-resonance low-temperature MAS probe. At $14.1 \mathrm{~T}$, the Larmor frequencies were $600.080 \mathrm{MHz}\left({ }^{1} \mathrm{H}\right)$, $150.905 \mathrm{MHz}\left({ }^{13} \mathrm{C}\right)$, and $60.813 \mathrm{MHz}\left({ }^{15} \mathrm{~N}\right)$. The microwave (MW) frequency was $395.18 \mathrm{GHz}$ and the MW irradiation generated by a second-harmonic gyrotron, which delivered $13.8 \mathrm{~W}$ of power, as calibrated at the probe waveguide entrance using a water load calorimeter. The measurements were performed at $120 \mathrm{~K}$, and the sample temperature was calibrated using $\mathrm{KBr}$ (Thurber and Tycko, 2009). All spectra were acquired at the MAS frequency of $24 \mathrm{kHz}$, controlled by a Bruker MAS3 controller. The typical $90^{\circ}$ pulse lengths were $1.5 \mu$ s $\left({ }^{1} \mathrm{H}\right)$ and $3 \mu$ s $\left({ }^{13} \mathrm{C}\right)$. The ${ }^{1} \mathrm{H}-{ }^{13} \mathrm{C}$ crosspolarization was performed with a tangential amplitude ramp on ${ }^{1} \mathrm{H}$ with the center of the ramp Hartmann-Hahn matched at the first spinning sideband; the carrier frequency on ${ }^{13} \mathrm{C}$ was set to $100 \mathrm{ppm}$; the $\mathrm{CP}$ contact time was $2 \mathrm{~ms}$. The ${ }^{13} \mathrm{C}$ DANTE (Bodenhausen et al., 1976) pulse length was 0.05 or $0.1 \mu$ s. The DANTE interpulse delay was set to one or two rotor cycles. The $2 \mathrm{D}{ }^{13} \mathrm{C}^{13} \mathrm{C}^{-C_{2}} \mathrm{COR}_{\mathrm{xy} 4}$ (Hou et al., 2013) mixing time was $20 \mathrm{~ms}$, corresponding to 480 rotor periods. The pulse sequences are shown in Fig. 1.

All spectra were processed in TopSpin 4.0 and analyzed in TopSpin 4.0 or NMRFAM-Sparky (Lee et al., 2015).

\section{Results and discussion}

${ }^{13} \mathrm{C}$ CPMAS and DPMAS NMR spectra of 5F-Trp, $\mathrm{U}_{-}{ }^{13} \mathrm{C}$, ${ }^{15} \mathrm{~N} \mathrm{CA}$ tubular assemblies acquired with a recycle delay of $10 \mathrm{~s}$ are displayed in Fig. $2 \mathrm{a}$ and b, respectively. The control spectra shown in the bottom traces, recorded with the microwave power turned off, reveal that the addition of biradical gives rise to concentration-dependent signal intensity loss. While this effect is modest in the CPMAS experiment for the sample prepared with $4.3 \mathrm{mM}$ AMUPol, in the DPMAS experiments the signal is attenuated considerably for all three biradical concentrations. Turning on microwaves at $13.8 \mathrm{~W}$ output power, a level sufficient to saturate the $\mathrm{CE}$ DNP mechanism (Lu et al., 2019), results in clear DNP signal enhancements. These enhancements in CPMAS experiments are large (76-, 73-, and 71-fold for samples containing $4.3,22.8$, and 28.2 mM AMUPol, respectively), positive, and only weakly dependent on the biradical concentration. This is not the case for the DPMAS spectra, where the enhancements are much smaller: 4.6-fold (4.3 mM AMUPol), 3.2fold (22.8 mM AMUPol), and 4.8-fold (28.2 mM AMUPol). Surprisingly, the DNP enhancement is negative for the sample prepared with $4.3 \mathrm{mM}$ AMUPol, while those for the samples containing 22.8 and $28.2 \mathrm{mM}$ AMUPol are positive. In addition, unexpectedly, while the spectral resolution of the non-enhanced and DNP-enhanced CPMAS spectra for these three samples and the DPMAS spectra of the $4.3 \mathrm{mM}$ AMUPol sample are similar, the lines are dramatically broadened in the DNP-enhanced DPMAS spectra of samples containing high AMUPol concentrations, 22.8 and $28.2 \mathrm{mM}$.

To gain further understanding of the origins of signal enhancements and spectral resolution in the three samples, we recorded DNP-enhanced CPMAS and DPMAS buildup profiles by varying the experimental recycle delay from $10 \mu \mathrm{s}$ to $64 \mathrm{~s}$. In conventional NMR, where a single variable $\left(T_{1}\right)$ governs longitudinal spin relaxation, the recycle delay is generally simply chosen to maximize signal-to-noise ratio per unit time (e.g., 1.3 $\cdot T_{1}$ ). The situation in DNP-NMR is significantly more complex: here, the recycle delay represents not only the longitudinal relaxation period, but also the polarization buildup time period, since microwaves are always 
(a)

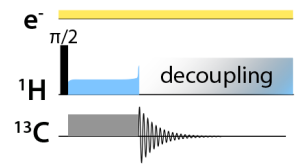

(b)

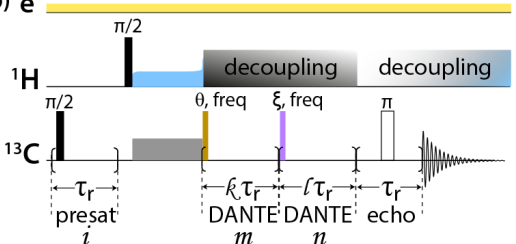

(d) $\mathrm{e}^{-}$

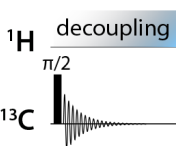

(e) $\mathrm{e}^{-}$
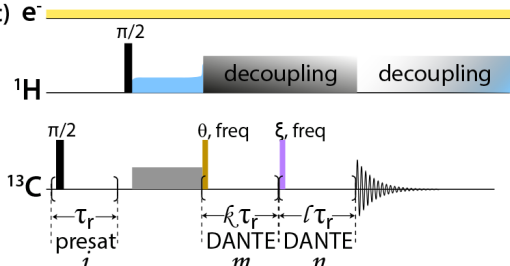

(f)

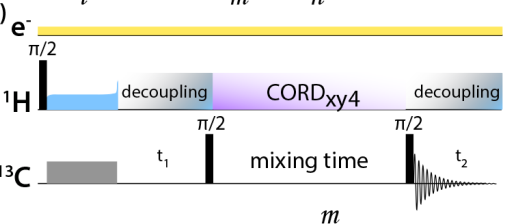

(h)

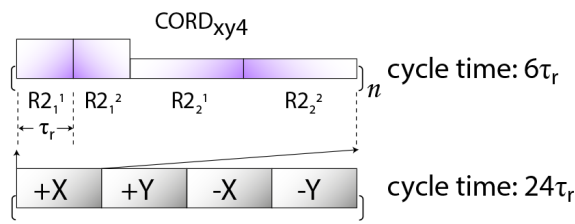

Figure 1. Pulse sequences for DNP-enhanced MAS NMR experiments: (a) CPMAS, (b) CPMAS with presaturation, selective DANTE flip and readout, and Hahn echo detection, (c) CPMAS with presaturation and selective DANTE flip and readout, (d) direct polarization, (e) direct polarization with selective DANTE excitation, (f) $2 \mathrm{D}$ CP-CORD $\mathrm{xy}_{4}$, and (g) DP-CORD $\mathrm{xy}_{4} \cdot$ (h) $\mathrm{CORD}_{\mathrm{xy} 4}$ mixing block.

(a) $\mathrm{CP}, 13.8 \mathrm{~W}$

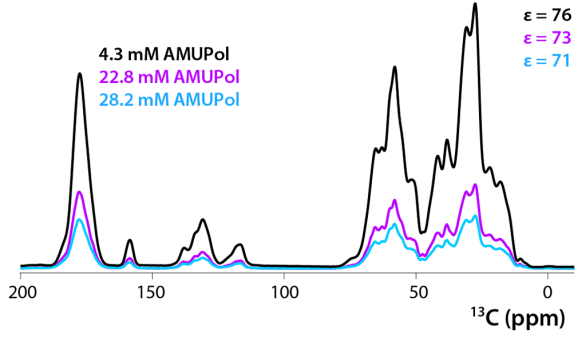

$C P, \mathrm{mw}$ off

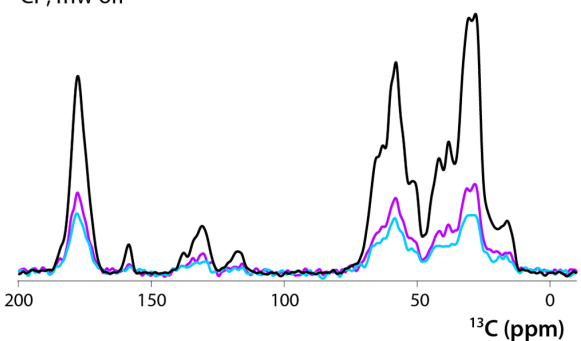

(b) direct polarization, $13.8 \mathrm{~W}$

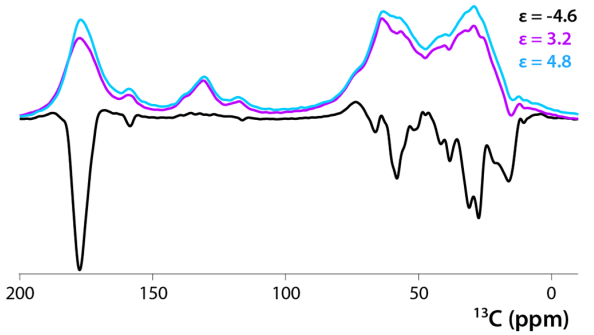

direct polarization, mw off

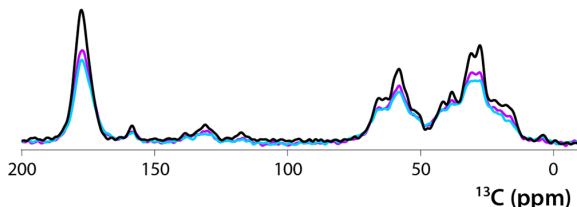

Figure 2. ${ }^{13} \mathrm{C}$ DNP-enhanced CP (a, top), DNP-enhanced direct polarization (b, top), CP (a, bottom), and direct polarization (b, bottom) MAS NMR spectra of 5F-Trp, U- ${ }^{13} \mathrm{C},{ }^{15} \mathrm{~N}$ CA tubular assemblies in the presence of $4.3 \mathrm{mM}$ AMUPol (black traces), $22.8 \mathrm{mM}$ AMUPol (magenta traces), and $28.2 \mathrm{mM}$ AMUPol (blue traces). The non-DNP enhanced CPMAS spectra (bottom panels) are direct intensities. For DNP-enhanced spectra (top panels) signal enhancements are indicated. The spectra were acquired at $14.1 \mathrm{~T}\left(150.96 \mathrm{MHz}{ }^{13} \mathrm{C} \mathrm{Larmor}\right.$ frequency) at a MAS frequency of $24 \mathrm{kHz}$ and $120 \mathrm{~K}$. The recycle delay was $10 \mathrm{~s}$ in all cases. 

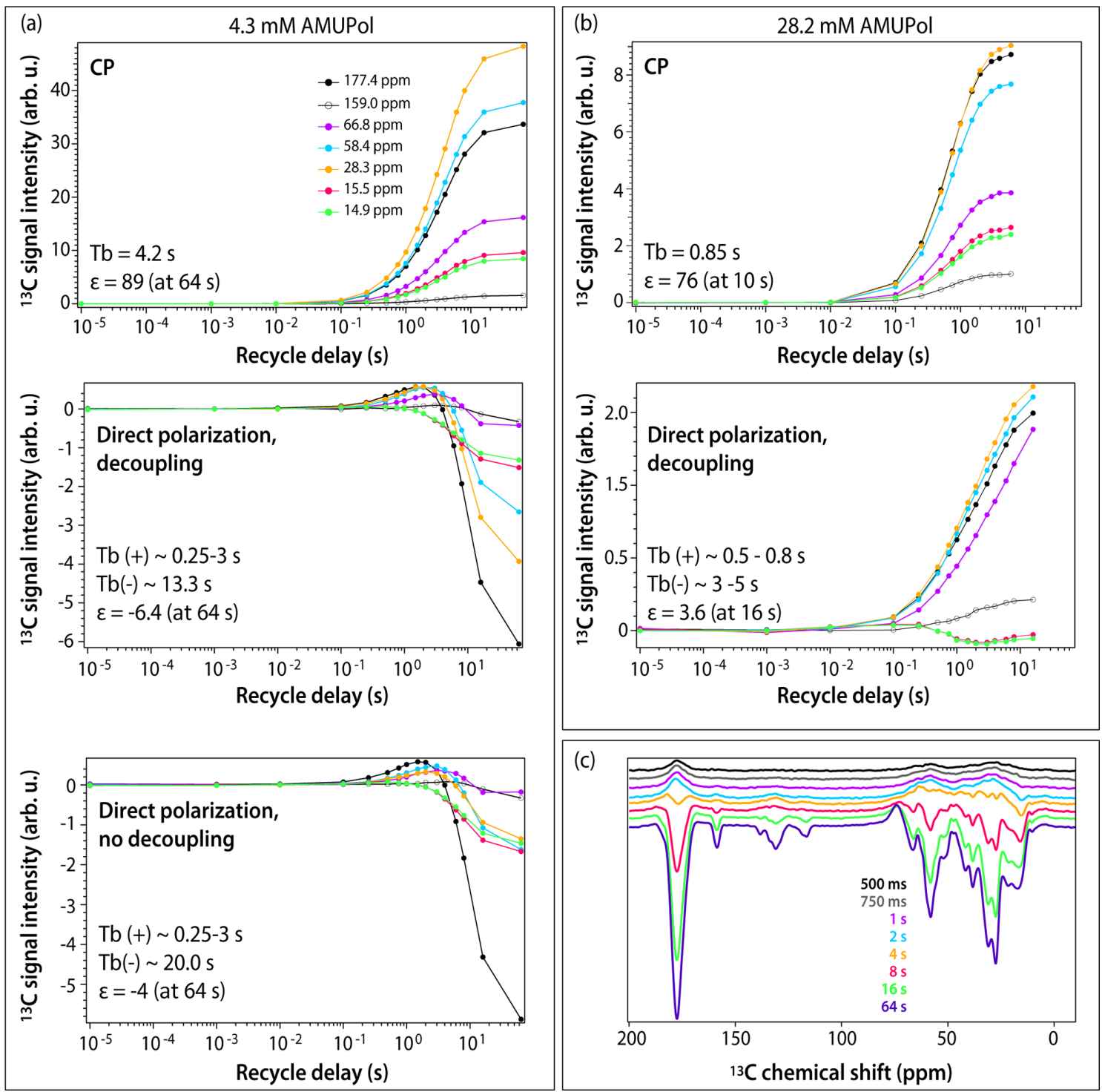

Figure 3. DNP buildup profiles for ${ }^{13} \mathrm{C}$ signals in DNP-enhanced spectra of $5 \mathrm{~F}-\mathrm{Trp}, \mathrm{U}-{ }^{13} \mathrm{C},{ }^{15} \mathrm{~N}$ CA tubular assemblies containing (a) $4.3 \mathrm{mM}$ AMUPol and (b) $28.2 \mathrm{mM}$ AMUPol. (a) Top, CPMAS spectra; middle, direct polarization spectra acquired with decoupling; bottom, direct polarization spectra acquired without decoupling. Signals corresponding to different functional groups are color-coded with the corresponding chemical shifts displayed in the topmost panel: carbonyl (177.4 ppm, black filled circles), aromatic (159.0 ppm, black open circles), $\mathrm{C} \alpha$ (66.8 ppm, magenta, $58.4 \mathrm{ppm}$, blue), $\mathrm{C} \beta / \mathrm{C} \gamma$ (28.3 ppm, gold), and Ile methyl groups (15.5 ppm, red, $14.9 \mathrm{ppm}$, green). The experimental buildup time constants $\left(T_{\mathrm{B}}\right)$ and the maximum signal enhancements $(\varepsilon)$ are indicated in each panel. (c) DNP-enhanced DPMAS spectra of $5 \mathrm{~F}-\mathrm{Trp}, \mathrm{U}_{-}{ }^{13} \mathrm{C},{ }^{15} \mathrm{~N}$ CA tubular assemblies containing $4.3 \mathrm{mM}$ AMUPol recorded with different recycle delays: $500 \mathrm{~ms}$ (blue), $750 \mathrm{~ms}$ (grey), $1 \mathrm{~s}$ (magenta), $2 \mathrm{~s}$ (blue), $4 \mathrm{~s}$ (gold), $8 \mathrm{~s}$ (red), $16 \mathrm{~s}$ (green), $64 \mathrm{~s}$ (purple). The spectra were acquired at $14.1 \mathrm{~T}\left(150.96 \mathrm{MHz}{ }^{13} \mathrm{C}\right.$ Larmor frequency) at a MAS frequency of $24 \mathrm{kHz}$ and $120 \mathrm{~K}$ sample temperature.

on throughout the experiment. If multiple DNP mechanisms are involved, each may have a different polarization buildup time constant $\left(T_{\mathrm{B}}\right)$, further varying by site on the molecule. The relationship between the experimental recycle delay and $T_{\mathrm{B}}$ governs the relative contributions of the various mechanisms. As a result, the DNP buildup profiles provide unique insight into the complex interplay of DNP effects. Profiles for different functional groups (carbonyl, aromatic, $\mathrm{C} \alpha, \mathrm{C} \beta / \mathrm{C} \gamma$, and Ile methyl groups) are displayed in Figs. 3 and S1 in the Supplement. For CPMAS experiments, the signals are positive, and the polarization buildup time constants, $T_{\mathrm{B}}$, become shorter as the biradical concentration increases, as expected.

The DPMAS DNP signal buildup profiles, on the other hand, are surprising. As shown in Fig. 3a (middle panel), for the $4.3 \mathrm{mM}$ AMUPol-containing sample, the signals for the Ile methyl groups (shown as green and red curves) are al- 
(a)

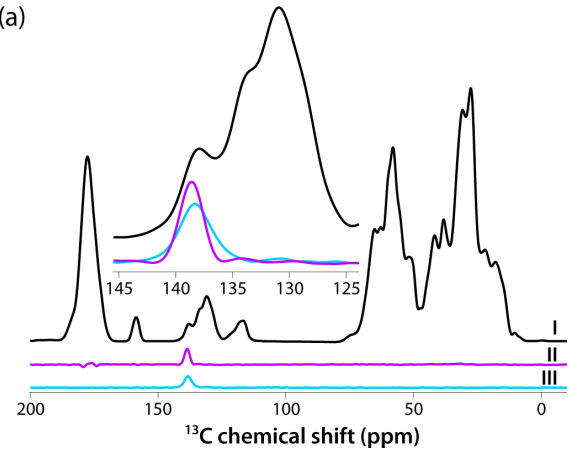

(b)

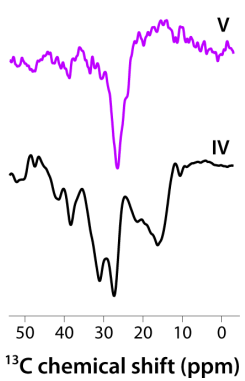

Figure 4. (a) CPMAS-based spectra acquired with pulse sequences shown in Fig. 1a-c are colored in black, magenta, and blue, respectively. The inset is an expansion around the aromatic region where the DANTE excitation pulse was applied (139 ppm). The homogeneous line width is $2.4 \mathrm{ppm}(362 \mathrm{~Hz})$. (b) Direct polarization spectra acquired using pulse sequences shown in Fig. 1d, e are colored in black and magenta, respectively. The homogeneous line width is $3.7 \mathrm{ppm}(559 \mathrm{~Hz})$. The spectra were acquired at $14.1 \mathrm{~T}(150.96 \mathrm{MHz}$ ${ }^{13} \mathrm{C}$ Larmor frequency) at a MAS frequency of $24 \mathrm{kHz}$ and $120 \mathrm{~K}$ sample temperature.

ways negative, but their enhancement increases with recycle delay, indicating that the polarization transfer proceeds via the SCREAM-DNP pathway (Aladin and Corzilius, 2019), emerging from the methyl groups and spreading slowly outward via ${ }^{13} \mathrm{C}$ spin diffusion. At the same time, the signals associated with other functional groups are small and positive and build up quickly within the first 1-2 s. At longer times, negative intensity signals appear and build up, reaching the maximum negative enhancement of 6.4-fold at a recycle delay of $64 \mathrm{~s}$. As expected, heteronuclear decoupling has no effect on these time dependencies, as shown in Fig. 3a (bottom panel): turning the decoupling off only results in broadening of the signals. Furthermore, as shown in Fig. 3c, at short polarization transfer time periods, the positive signals are very broad, while the negative signals arising at long polarization transfer time periods are narrow.

Taken together, this suggests that at short polarization transfer time periods, for the sample with $4.3 \mathrm{mM}$ AMUPol, the SCREAM-DNP pathway is operational for the Ile methyl groups, while direct DNP transfer occurs for the remainder of the functional groups. At polarization transfer times exceeding $4 \mathrm{~s}$, SCREAM-DNP is gradually relayed by ${ }^{13} \mathrm{C}$ spin diffusion and becomes the dominant pathway throughout, yielding only negative signals and overall larger enhancements.

For the sample prepared with $28.2 \mathrm{mM}$ AMUPol, SCREAM-DNP polarization transfer occurs for the Ile methyl groups, with negative signals building up until $2 \mathrm{~s}$, after which the signal intensities decrease with the sign remaining negative. (This is different from the corresponding signal behavior in the $4.3 \mathrm{mM}$ AMUPol sample, where the negative intensity builds up until $64 \mathrm{~s}$; see above.) Interestingly, all other functional groups are polarized via a direct

pathway, with no evidence of SCREAM-DNP polarization occurring up to $16 \mathrm{~s}$ buildup time. The signals remain broad at all buildup times.

Intrigued by the relatively narrow lines in both CPMAS and DPMAS spectra acquired with $10 \mathrm{~s}$ recycle delay for the sample prepared with $4.3 \mathrm{mM}$ AMUPol, we assessed the homogeneous line widths in each case. To this end, we performed selective-excitation experiments using DANTE pulse trains, whose performance in terms of selectivity was optimized experimentally. The pulse sequences are shown in Fig. 1. Three CP-based experiments were performed: (I) conventional CPMAS as a control; (II) an experiment with ${ }^{13} \mathrm{C}$ signal presaturation preceding $\mathrm{CP}$ (to eliminate any residual magnetization), followed by $\mathrm{CP}$, double DANTE flipback/readout pulse train, and Hahn echo; and (III) an experiment with ${ }^{13} \mathrm{C}$ signal presaturation preceding $\mathrm{CP}$ (to eliminate any residual magnetization), followed by $\mathrm{CP}$ and double DANTE flipback/readout pulse train. The corresponding spectra are displayed in Fig. 4a. It is clear that experiment II has the highest selectivity, and the peak width is $2.4 \mathrm{ppm}(362 \mathrm{~Hz})$. We also recorded two DP-based experiments: (IV) a control with non-selective excitation and (V) a selective DANTE-excitation spectrum. Both are shown in Fig. 4b. The peak width in the DANTE-excitation spectrum is $3.7 \mathrm{ppm}(559 \mathrm{~Hz})$, considerably broader than in the CP-based data sets.

Recognizing that the apparent broader line widths in the above 1D selective-excitation experiments may be associated with different sites in the uniformly ${ }^{13} \mathrm{C}$-labeled protein, we performed 2D CP-CORD and DP-CORD experiments on the samples prepared with $4.3 \mathrm{mM}$ and $28.2 \mathrm{mM}$ AMUPol. The corresponding spectra are displayed in Fig. 5a and b, respectively. The CP-CORD spectra acquired with a recycle delay of $5 \mathrm{~s}$ (left panels) are relatively well-resolved, with line widths of the individual resonances ranging from 0.8 to $1 \mathrm{ppm}$ and 1.4 to $1.8 \mathrm{ppm}$ for 4.3 and $28.2 \mathrm{mM}$ AMUPolcontaining samples, respectively.

In contrast to the relatively narrow lines in the CP-CORD spectra, the resolution in the DP-CORD spectra with a $1.5 \mathrm{~s}$ recycle delay is very poor for both samples (middle panels of Fig. 5a and b), with SCREAM-DNP serving as the polarization transfer pathway for Ile methyl groups (negative peaks, purple) and direct transfer being operational for the rest of the functional groups (positive peaks). It is apparent that paramagnetic line broadening is severe, and the spectra appear to report selectively on surface residues. For the few resolved cross peaks, the line widths are on the order of $3 \mathrm{ppm}$ in both spectra.

The DP-CORD spectrum with a $10 \mathrm{~s}$ recycle delay for the sample containing $4.3 \mathrm{mM}$ AMUPol is shown in Fig. 5a, right panel. Interestingly, the spectral resolution is reasonably good, with the line widths of the individual resonances ranging from 1.5 to $1.8 \mathrm{ppm}$. While many cross peaks superimpose well on those in the CP-CORD spectra, a number of resonances that are present in DP-CORD data sets are miss- 

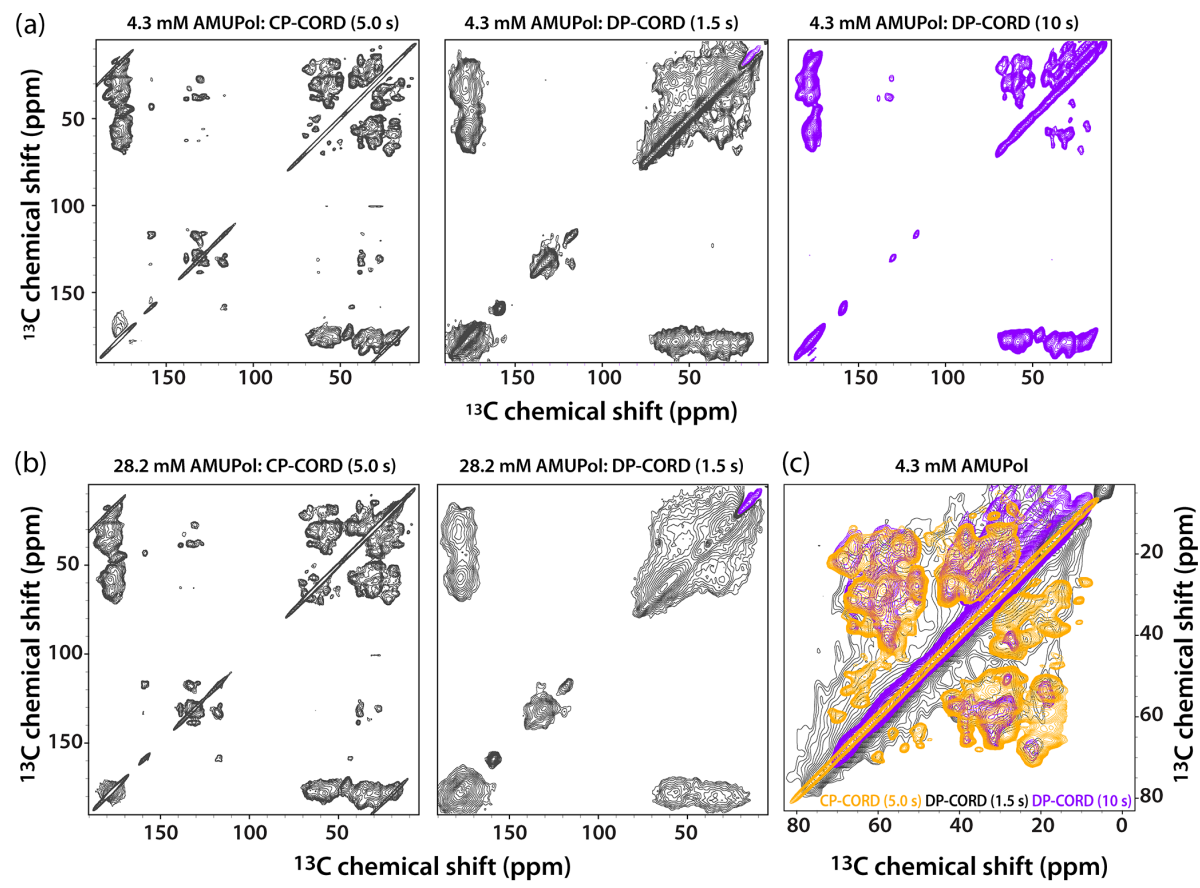

(d)

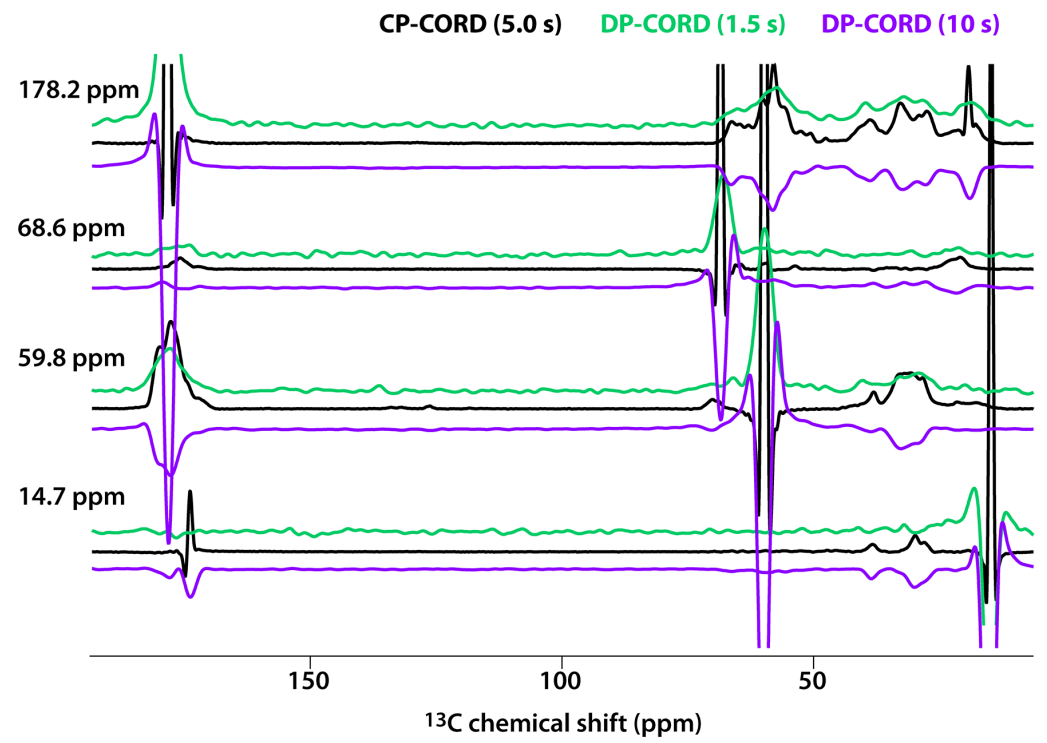

Figure 5. DNP-enhanced CP-CORD (left) and DP-CORD (middle and right) spectra of $5 \mathrm{~F}-\mathrm{Trp}, \mathrm{U}-{ }^{13} \mathrm{C},{ }^{15} \mathrm{~N}$ tubular CA assemblies in the presence of $4.3 \mathrm{mM}$ AMUPol (a) and $28.2 \mathrm{mM}$ AMUPol (b). The recycle delay in the CP-CORD spectra was $5 \mathrm{~s}$, in the DP-CORD spectra $1.5 \mathrm{~s}$ (middle) and $10 \mathrm{~s}$ (right). The CORD mixing time was $20 \mathrm{~ms}$. The positive and negative signals are shown in black and magenta, respectively. (c) The superposition of DNP-enhanced spectra shown in (a): CP-CORD (gold), DP-CORD with a recycle delay of $1.5 \mathrm{~s}$ (black), and DP-CORD with a recycle delay of $10 \mathrm{~s}$ (magenta). (d) Representative 1D traces extracted from 2D CP-CORD (black), DPCORD (recycle delay $1.5 \mathrm{~s}$, green), and DP-CORD (recycle delay $10 \mathrm{~s}$, purple) spectra of $5 \mathrm{~F}-\mathrm{Trp}, \mathrm{U}-{ }^{13} \mathrm{C},{ }^{15} \mathrm{~N}$ tubular CA assemblies in the presence of $4.3 \mathrm{mM}$ AMUPol. All spectra were acquired at $14.1 \mathrm{~T}\left(150.96 \mathrm{MHz}{ }^{13} \mathrm{C}\right.$ Larmor frequency) at a MAS frequency of $24 \mathrm{kHz}$ and $120 \mathrm{~K}$.

ing in CP-CORD spectra and vice versa (Fig. 5c). The different resolution of the CP-CORD and DP-CORD data sets acquired with different recycle delays is evident in the representative 1D traces extracted from the spectra; see Fig. 5d.
The superposition of DNP-enhanced CP-CORD spectra of samples prepared with $4.3 \mathrm{mM}$ AMUPol (gold contours) and $28.2 \mathrm{mM}$ AMUPol (black contours) is displayed in Fig. 6 . As can be appreciated, the overall spectral resolution is comparable (if somewhat lower in the $28.2 \mathrm{mM}$ AMUPol- 

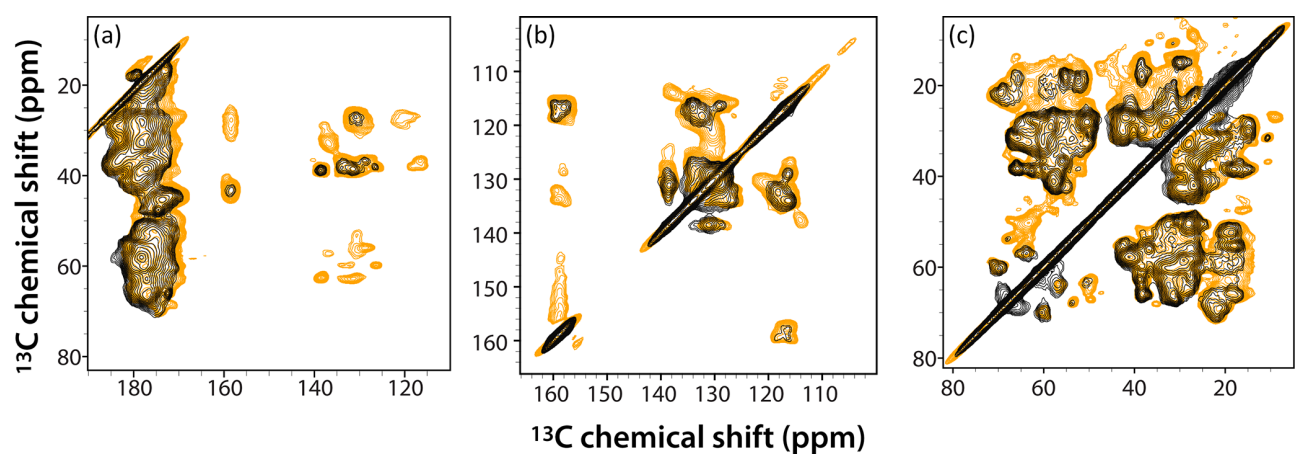

Figure 6. Superposition of DNP-enhanced CP-CORD spectra of 5 F-Trp, $\mathrm{U}_{-}{ }^{13} \mathrm{C},{ }^{15} \mathrm{~N}$ tubular CA assemblies in the presence of $4.3 \mathrm{mM}$ AMUPol (gold) and $28.2 \mathrm{mM}$ AMUPol (black). Expanded regions of the spectra around carbonyl-aliphatic/aromatic-aliphatic (a), aromatic (b), and aliphatic (c) are shown. The recycle delay was $5 \mathrm{~s}$ and the CORD mixing time was 20 ms. The spectra were acquired at $14.1 \mathrm{~T}\left(150.96 \mathrm{MHz}{ }^{13} \mathrm{C}\right.$ Larmor frequency) at a MAS frequency of $24 \mathrm{kHz}$ and $120 \mathrm{~K}$ sample temperature.

containing spectrum), and many cross peaks are missing at the higher AMUPol concentration.

\section{Conclusions}

Using tubular assemblies of HIV-1 CA protein as a model system, we discovered that all three DNP polarization transfer pathways - indirect, direct, and SCREAM-DNP - are simultaneously active and can be emphasized or selected by carefully choosing specific sample conditions and/or experimental set-ups. While the indirect DNP pathway results in the highest signal enhancements and narrowest lines, direct DNP-based experiments permit the identification of surface sites in close proximity to the radical in these tubular assemblies. Taken together, our results also suggest that for attaining high enhancements and spectral resolution simultaneously, there may be no advantage to using high biradical concentrations: for our current sample, $4.3 \mathrm{mM}$ AMUPol yielded the highest DNP signal enhancements and the best resolution. Conversely, high biradical concentrations can be employed to selectively bleach surface signals, allowing one to focus on other sites. We envision that our findings may provide valuable guidance for structural investigations of other biological assemblies by DNP MAS NMR.

Data availability. NMR data reported in this work are available from the authors by request.

Supplement. Buildup profile for ${ }^{13} \mathrm{C}$ signals in DNP-enhanced CPMAS spectra of tubular assemblies of 5F-Trp, U- ${ }^{13} \mathrm{C},{ }^{15} \mathrm{~N} \mathrm{CA}$ containing $22.8 \mathrm{mM}$ AMUPol. The supplement related to this article is available online at: https://doi.org/10.5194/mr-2-239-2021supplement.
Author contributions. TP, IVS, and AMG conceived the study. IVS, TP, and CMQ performed the NMR experiments. TP and IVS analyzed the data. TP took the lead in writing the manuscript. All the authors discussed the results and contributed to the manuscript preparation.

Competing interests. The authors declare that they have no conflict of interest.

Special issue statement. This article is part of the special issue "Robert Kaptein Festschrift". It is not associated with a conference.

Acknowledgements. We are grateful for the support of the National Institutes of Health $(\mathrm{NIH})$ of the work on this project and of the core instrumentation infrastructure at the University of Delaware. This work is a contribution of the Pittsburgh Center for HIV Protein Interactions (PCHPI). We thank Manman Lu and Mingzhang Wang for DNP sample preparations.

Financial support. This research has been supported by the National Institutes of Health (NIH grant no. P50AI150481) and is a contribution from the Pittsburgh Center for HIV Protein Interactions. We have also received support from the National Institutes of Health (NIH grant no. P30GM110758) for the support of core instrumentation infrastructure at the University of Delaware.

Review statement. This paper was edited by Rolf Boelens and reviewed by Björn Corzilius, Anja Böckmann, and one anonymous referee.

\section{References}

Akbey, Ü., Franks, W. T., Linden, A., Lange, S., Griffin, R. G., van Rossum, B.-J., and Oschkinat, H.: Dynamic Nuclear Polarization 
of Deuterated Proteins, Angew. Chem. Int. Ed. Engl., 49, 78037806, https://doi.org/10.1002/anie.201002044, 2010.

Aladin, V. and Corzilius, B.: Methyl Dynamics in Amino Acids Modulate Heteronuclear Cross Relaxation in the Solid State Under MAS DNP, Solid State Nucl. Mag., 99, 27-35, https://doi.org/10.1016/j.ssnmr.2019.02.004, 2019.

Aladin, V. and Corzilius, B.: Direct Dynamic Nuclear Polarization as a Tool or Selective NMR Spectroscopy of Biomolecules, eMagRes, 9, 239-249, https://doi.org/10.1002/9780470034590.emrstm1597, 2020.

Albert, B. J., Gao, C., Sesti, E. L., Saliba, E. P., Alaniva, N., Scott, F. J., Sigurdsson, S. T., and Barnes, A. B.: Dynamic Nuclear Polarization Nuclear Magnetic Resonance in Human Cells Using Fluorescent Polarizing Agents, Biochemistry, 57, 4741-4746, https://doi.org/10.1021/acs.biochem.8b00257, 2018.

Bajaj, V. S., Farrar, C. T., Hornstein, M. K., Mastovsky, I., Vieregg, J., Bryant, J., Elena, B., Kreischer, K. E., Temkin, R. J., and Griffin, R. G.: Dynamic Nuclear Polarization at 9 T Using a Novel $250 \mathrm{GHz}$ Gyrotron Microwave Source, J. Magn. Reson., 160, 8590, https://doi.org/10.1016/S1090-7807(02)00192-1, 2003.

Bayro, M. J., Debelouchina, G. T., Eddy, M. T., Birkett, N. R., MacPhee, C. E., Rosay, M., Maas, W. E., Dobson, C. M., and Griffin, R. G.: Intermolecular Structure Determination of Amyloid Fibrils with Magic-Angle Spinning and Dynamic Nuclear Polarization NMR, J. Am. Chem. Soc., 133, 13967-13974, https://doi.org/10.1021/ja203756x, 2011.

Berruyer, P., Björgvinsdóttir, S., Bertarello, A., Stevanato, G., Rao, Y., Karthikeyan, G., Casano, G., Ouari, O., Lelli, M., Reiter, C., Engelke, F., and Emsley, L.: Dynamic Nuclear Polarization Enhancement of 200 at $21.15 \mathrm{~T}$ Enabled by $65 \mathrm{kHz}$ Magic Angle Spinning, J. Phys. Chem. Lett., 11, 8386-8391, https://doi.org/10.1021/acs.jpclett.0c02493, 2020.

Bodenhausen, G., Freeman, R., and Morris, G. A.: A Simple Pulse Sequence for Selective Excitation in Fourier transform NMR, J. Magn. Reson., 23, 171-175, https://doi.org/10.1016/00222364(76)90150-5, 1976.

Can, T. V., Ni, Q. Z., and Griffin, R. G.: Mechanisms of Dynamic Nuclear Polarization in Insulating Solids, J. Magn. Reson., 253, 23-35, https://doi.org/10.1016/j.jmr.2015.02.005, 2015.

Cheng, C.-Y. and Han, S.: Dynamic Nuclear Polarization Methods in Solids and Solutions to Explore Membrane Proteins and Membrane Systems, Annu. Rev. Phys. Chem., 64, 507-532, https://doi.org/10.1146/annurev-physchem-040412-110028, 2013.

Debelouchina, G. T., Bayro, M. J., van der Wel, P. C. A., Caporini, M. A., Barnes, A. B., Rosay, M., Maas, W. E., and Griffin, R. G.: Dynamic Nuclear Polarization-Enhanced SolidState NMR Spectroscopy of GNNQQNY Nanocrystals and Amyloid Fibrils, Phys. Chem. Chem. Phys., 12, 5911-5919, https://doi.org/10.1039/C003661G, 2010.

Debelouchina, G. T., Bayro, M. J., Fitzpatrick, A. W., Ladizhansky, V., Colvin, M. T., Caporini, M. A., Jaroniec, C. P., Bajaj, V. S., Rosay, M., MacPhee, C. E., Vendruscolo, M., Maas, W. E., Dobson, C. M., and Griffin, R. G.: Higher Order Amyloid Fibril Structure by MAS NMR and DNP Spectroscopy, J. Am. Chem. Soc., 135, 19237-19247, https://doi.org/10.1021/ja409050a, 2013.

Frederick, K. K., Michaelis, V. K., Caporini, M. A., Andreas, L. B., Debelouchina, G. T., Griffin, R. G., and Lindquist, S.:
Combining DNP NMR With Segmental and Specific Labeling to Study a Yeast Prion Protein Strain that Is Not Parallel In-Register, P. Natl. Acad. Sci. USA, 114, 3642-3647, https://doi.org/10.1073/pnas.1619051114, 2017.

Fricke, P., Mance, D., Chevelkov, V., Giller, K., Becker, S., Baldus, M., and Lange, A.: High Resolution Observed in $800 \mathrm{MHz}$ DNP Spectra of Extremely Rigid Type III Secretion Needles, J. Biomol. NMR, 65, 121-126, https://doi.org/10.1007/s10858016-0044-y, 2016.

Geiger, M.-A., Orwick-Rydmark, M., Märker, K., Franks, W. T., Akhmetzyanov, D., Stöppler, D., Zinke, M., Specker, E., Nazaré, M., Diehl, A., van Rossum, B.-J., Aussenac, F., Prisner, T., Akbey, Ü., and Oschkinat, H.: Temperature Dependence of CrossEffect Dynamic Nuclear Polarization in Rotating Solids: Advantages of Elevated Temperatures, Phys. Chem. Chem. Phys., 18, 30696-30704, https://doi.org/10.1039/C6CP06154K, 2016.

Gupta, R., Lu, M., Hou, G., Caporini, M. A., Rosay, M., Maas, W., Struppe, J., Suiter, C., Ahn, J., Byeon, I.-J. L., Franks, W. T., Orwick-Rydmark, M., Bertarello, A., Oschkinat, H., Lesage, A., Pintacuda, G., Gronenborn, A. M., and Polenova, T.: Dynamic Nuclear Polarization Enhanced MAS NMR Spectroscopy for Structural Analysis of HIV1 Protein Assemblies, J. Phys. Chem. B, 120, 329-339, https://doi.org/10.1021/acs.jpcb.5b12134, 2016.

Gupta, R., Zhang, H., Lu, M., Hou, G., Caporini, M., Rosay, M., Maas, W., Struppe, J., Ahn, J., Byeon, I. L., Oschkinat, H., Jaudzems, K., Barbet-Massin, E., Emsley, L., Pintacuda, G., Lesage, A., Gronenborn, A. M., and Polenova, T.: Dynamic Nuclear Polarization Magic-Angle Spinning Nuclear Magnetic Resonance Combined with Molecular Dynamics Simulations Permits Detection of Order and Disorder in Viral Assemblies, J. Phys. Chem. B, 123, 5048-5058, https://doi.org/10.1021/acs.jpcb.9b02293, 2019.

Hou, G., Yan, S., Trebosc, J., Amoureux, J. P., and Polenova, T.: Broadband Homonuclear Correlation Spectroscopy Driven by Combined $\mathrm{R} 2{ }_{n}^{v}$ Sequences Under Fast Magic Angle Spinning for NMR Structural Analysis of Organic and Biological Solids, J. Magn. Reson., 232, 18-30, https://doi.org/10.1016/j.jmr.2013.04.009, 2013.

Hu, K.-N., Yu, H.-h., Swager, T. M., and Griffin, R. G.: Dynamic Nuclear Polarization with Biradicals, J. Am. Chem. Soc., 126, 10844-10845, https://doi.org/10.1021/ja039749a, 2004.

Jaudzems, K., Bertarello, A., Chaudhari, S. R., Pica, A., CalaDe Paepe, D., Barbet-Massin, E., Pell, A. J., Akopjana, I., Kotelovica, S., Gajan, D., Ouari, O., Tars, K., Pintacuda, G., and Lesage, A.: Dynamic Nuclear Polarization-Enhanced Biomolecular NMR Spectroscopy at High Magnetic Field with Fast Magic-Angle Spinning, Angew. Chem. Int. Ed. Engl., 57, 74587462, https://doi.org/10.1002/anie.201801016, 2018.

Jaudzems, K., Polenova, T., Pintacuda, G., Oschkinat, H., and Lesage, A.: DNP NMR of Biomolecular Assemblies, J. Struct. Biol., 206, 90-98, https://doi.org/10.1016/j.jsb.2018.09.011, 2019.

Jeon, J., Thurber, K. R., Ghirlando, R., Yau, W. M., and Tycko, R.: Application of Millisecond Time-Resolved Solid State NMR to the Kinetics and Mechanism of Melittin Self-Assembly, P. Natl. Acad. Sci. USA, 116, 16717-16722, https://doi.org/10.1073/pnas.1908006116, 2019. 
Judge, P. T., Sesti, E. L., Price, L. E., Albert, B. J., Alaniva, N., Saliba, E. P., Halbritter, T., Sigurdsson, S. T., Kyei, G. B., and Barnes, A. B.: Dynamic Nuclear Polarization with Electron Decoupling in Intact Human Cells and Cell Lysates, J. Phys. Chem. B, 124, 2323-2330, https://doi.org/10.1021/acs.jpcb.9b10494, 2020.

Koers, E. J., López-Deber, M. P., Weingarth, M., Nand, D., Hickman, D. T., Mlaki Ndao, D., Reis, P., Granet, A., Pfeifer, A., Muhs, A., and Baldus, M.: Dynamic Nuclear Polarization NMR Spectroscopy: Revealing Multiple Conformations in LipidAnchored Peptide Vaccines, Angew. Chem. Int. Ed. Engl., 52, 10905-10908, https://doi.org/10.1002/anie.201303374, 2013.

König, A., Schölzel, D., Uluca, B., Viennet, T., Akbey, Ü., and Heise, H.: Hyperpolarized MAS NMR of Unfolded and Misfolded Proteins, Solid State Nucl. Mag., 98, 1-11, https://doi.org/10.1016/j.ssnmr.2018.12.003, 2019.

Lee, W., Tonelli, M., and Markley, J. L.: NMRFAMSPARKY: Enhanced Software for Biomolecular NMR Spectroscopy, Bioinformatics, 31, 1325-1327, https://doi.org/10.1093/bioinformatics/btu830, 2015.

Liao, S. Y., Lee, M., Wang, T., Sergeyev, I. V., and Hong, M.: Efficient DNP NMR of membrane proteins: sample preparation protocols, sensitivity, and radical location, J. Biomol. NMR, 64, 223-237, https://doi.org/10.1007/s10858-016-0023-3, 2016.

Linden, A. H., Franks, W. T., Akbey, U., Lange, S., van Rossum, B. J., and Oschkinat, H.: Cryogenic Temperature Effects and Resolution upon Slow Cooling of Protein Preparations in Solid State NMR, J. Biomol. NMR, 51, 283-292, https://doi.org/10.1007/s10858-011-9535-z, 2011.

Lu, M., Wang, M., Sergeyev, I. V., Quinn, C. M., Struppe, J., Rosay, M., Maas, W., Gronenborn, A. M., and Polenova, T.: ${ }^{19}$ F Dynamic Nuclear Polarization at Fast Magic Angle Spinning for NMR of HIV-1 Capsid Protein Assemblies, J. Am. Chem. Soc., 141, 5681-5691, https://doi.org/10.1021/jacs.8b09216, 2019.

Maly, T., Cui, D., Griffin, R. G., and Miller, A.-F.: ${ }^{1} \mathrm{H}$ Dynamic Nuclear Polarization Based on an Endogenous Radical, J. Phys. Chem. B, 116, 7055-7065, https://doi.org/10.1021/jp300539j, 2012.

Ravera, E., Michaelis, V. K., Ong, T.-C., Keeler, E. G., Martelli, T., Fragai, M., Griffin, R. G., and Luchinat, C.: Biosilica-Entrapped Enzymes Can Be Studied by DNPEnhanced High-Field NMR, ChemPhysChem, 16, 2751-2754, https://doi.org/10.1002/cphc.201500549, 2015.

Rogawski, R., Sergeyev, I. V., Zhang, Y., Tran, T. H., Li, Y. J., Tong, L., and McDermott, A. E.: NMR Signal Quenching from Bound Biradical Affinity Reagents in DNP Samples, J. Phys. Chem. B, 121, 10770-10781, https://doi.org/10.1021/acs.jpcb.7b08274, 2017.

Rosay, M., Zeri, A.-C., Astrof, N. S., Opella, S. J., Herzfeld, J., and Griffin, R. G.: Sensitivity-Enhanced NMR of Biological Solids: Dynamic Nuclear Polarization of Y21M fd Bacteriophage and Purple Membrane, J. Am. Chem. Soc., 123, 10101011, https://doi.org/10.1021/ja005659j, 2001.

Rosay, M., Lansing, J. C., Haddad, K. C., Bachovchin, W. W., Herzfeld, J., Temkin, R. J., and Griffin, R. G.: High-Frequency Dynamic Nuclear Polarization in MAS Spectra of Membrane and Soluble Proteins, J. Am. Chem. Soc., 125, 13626-13627, https://doi.org/10.1021/ja036898k, 2003.
Salnikov, E. S., Abel, S., Karthikeyan, G., Karoui, H., Aussenac, F., Tordo, P., Bechinger, B., and Ouari, O.: Dynamic Nuclear Polarization/Solid-State NMR Spectroscopy of Membrane Polypeptides: Free-Radical Optimization for MatrixFree Lipid Bilayer Samples, ChemPhysChem, 18, 2103-2113, https://doi.org/10.1002/cphc.201700389, 2017.

Sauvée, C., Rosay, M., Casano, G., Aussenac, F., Weber, R. T., Ouari, O., and Tordo, P.: Highly Efficient, Water-Soluble Polarizing Agents for Dynamic Nuclear Polarization at High Frequency, Angew. Chem. Int. Ed. Engl., 52, 10858-10861, https://doi.org/10.1002/anie.201304657, 2013.

Sergeyev, I. V., Day, L. A., Goldbourt, A., and McDermott, A. E.: Chemical Shifts for the Unusual DNA Structure in Pf1 Bacteriophage from Dynamic-Nuclear-Polarization-Enhanced SolidState NMR Spectroscopy, J. Am. Chem. Soc., 133, 2020820217, https://doi.org/10.1021/ja2043062, 2011.

Sergeyev, I. V., Itin, B., Rogawski, R., Day, L. A., and McDermott, A. E.: Efficient Assignment and NMR Analysis of an Intact Virus Using Sequential Side-Chain Correlations and DNP Sensitization, P. Natl. Acad. Sci. USA, 114, 5171-5176, https://doi.org/10.1073/pnas.1701484114, 2017.

Smith, A. N., Caporini, M. A., Fanucci, G. E., and Long, J. R.: A Method for Dynamic Nuclear Polarization Enhancement of Membrane Proteins, Angew. Chem. Int. Ed. Engl., 54, 15421546, https://doi.org/10.1002/anie.201410249, 2015.

Song, C., Hu, K.-N., Joo, C.-G., Swager, T. M., and Griffin, R. G.: TOTAPOL: A Biradical Polarizing Agent for Dynamic Nuclear Polarization Experiments in Aqueous Media, J. Am. Chem. Soc., 128, 11385-11390, https://doi.org/10.1021/ja061284b, 2006.

Takahashi, H., Lee, D., Dubois, L., Bardet, M., Hediger, S., and De Paëpe, G.: Rapid Natural-Abundance $2 \mathrm{D}{ }^{13} \mathrm{C}-$ ${ }^{13} \mathrm{C}$ Correlation Spectroscopy Using Dynamic Nuclear Polarization Enhanced Solid-State NMR and Matrix-Free Sample Preparation, Angew. Chem. Int. Ed., 51, 11766-11769, https://doi.org/10.1002/anie.201206102, 2012.

Thankamony, A. S. L., Wittmann, J. J., Kaushik, M., and Corzilius, B.: Dynamic Nuclear Polarization for Sensitivity Enhancement in Modern Solid-State NMR, Prog. Nucl. Magn. Reson. Spectrosc., 102, 120-195, https://doi.org/10.1016/j.pnmrs.2017.06.002, 2017.

Thurber, K. R. and Tycko, R.: Measurement of Sample Temperatures Under Magic-Angle Spinning from the Chemical Shift and Spin-Lattice Relaxation Rate of ${ }^{79} \mathrm{Br}$ in $\mathrm{KBr}$ Powder, J. Magn. Reson., 196, 84-87, https://doi.org/10.1016/j.jmr.2008.09.019, 2009.

Tran, N. T., Mentink-Vigier, F., and Long, J. R.: Dynamic Nuclear Polarization of Biomembrane Assemblies, Biomolecules, 10, 1246, https://doi.org/10.3390/biom10091246, 2020.

van der Wel, P. C. A., Hu, K.-N., Lewandowski, J., and Griffin, R. G.: Dynamic Nuclear Polarization of Amyloidogenic Peptide Nanocrystals: GNNQQNY, a Core Segment of the Yeast Prion Protein Sup35p, J. Am. Chem. Soc., 128, 10840-10846, https://doi.org/10.1021/ja0626685, 2006.

Viennet, T., Viegas, A., Kuepper, A., Arens, S., Gelev, V., Petrov, O., Grossmann, T. N., Heise, H., and Etzkorn, M.: Selective Protein Hyperpolarization in Cell Lysates Using Targeted Dynamic Nuclear Polarization, Angew. Chem. Int. Ed. Engl., 55, 1074610750, https://doi.org/10.1002/anie.201603205, 2016. 
Viger-Gravel, J., Schantz, A., Pinon, A. C., Rossini, A. J., Schantz, S., and Emsley, L.: Structure of Lipid Nanoparticles Containing siRNA or mRNA by Dynamic Nuclear PolarizationEnhanced NMR Spectroscopy, J. Phys. Chem. B, 122, 20732081, https://doi.org/10.1021/acs.jpcb.7b10795, 2018.

Wenk, P., Kaushik, M., Richter, D., Vogel, M., Suess, B., and Corzilius, B.: Dynamic Nuclear Polarization of Nucleic Acid with Endogenously Bound Manganese, J. Biomol. NMR, 63, 97-109, https://doi.org/10.1007/s10858-015-9972-1, 2015.
Wylie, B. J., Dzikovski, B. G., Pawsey, S., Caporini, M., Rosay, M., Freed, J. H., and McDermott, A. E.: Dynamic Nuclear Polarization of Membrane Proteins: Covalently Bound Spin-Labels at Protein-Protein Interfaces, J. Biomol. NMR, 61, 361-367, https://doi.org/10.1007/s10858-015-9919-6, 2015.

Yamamoto, K., Caporini, M. A., Im, S.-C., Waskell, L., and Ramamoorthy, A.: Cellular Solid-State NMR Investigation of a Membrane Protein Using Dynamic Nuclear Polarization, BBA-Biomembranes, 1848, 342-349, https://doi.org/10.1016/j.bbamem.2014.07.008, 2015. 